\title{
PRODUTIVIDADE, TRANSPARÊNCIA E ESTATUTO PROSÓDICO DE PALAVRAS DERIVADAS POR PREFIXAÇÃO EM PORTUGÊS BRASILEIRO E ESPANHOL PENINSULAR* \\ - Luiz Carlos Schwindt -
}

RESUMO: In this paper we present a study about the prosodic status of prefixed words in Brazilian Portuguese and Peninsular Spanish. Considering the theoretical framework of the Prosodic Phonology (Selkirk, 1984, 1986; Nespor \& Vogel, 1986), we assume that the monosyllabic prefixes in the described languages are split in two categories: the incorporated prefixes (transparent but not necessarily productive) and the adjoined prefixes (obligatorily transparent and productive).

PALAVRAS-CHAVE: Prefixos. Morfologia. Fonologia. Prosódia.

\section{INTRODUÇÃO}

Este trabalho tem basicamente dois objetivos: (i) refletir sobre o status prosódico de prefixos monossilábicos inacentuados no português brasileiro (PB) e no espanhol peninsular (EP); e (ii) propor uma estratificação do léxico que dê conta da transparência/produtividade desses prefixos.

Assim, o texto está organizado como segue. $\mathrm{Na}$ seção 2, apresentamos uma proposta de configuração prosódica dos prefixos nas duas línguas, fundamentados na análise de Schwindt (2000). Na seção 3, apresentamos uma descrição dos prefixos transparentes nesses dois sistemas, trazendo à tona as análises de Peperkamp (1997) e de Vigário (2001), e finalizamos com uma proposta de estratificação do léxico que procura dar conta do caráter de produtividade/transparência desses morfemas. Em 4, estão nossas conclusões.

\section{CONFIGURAÇÃO PROSÓDICA DE PREFIXOS EM PB E EP}

Em Schwindt (2000) propusemos que os prefixos do $\mathrm{PB}$ dividem-se em dois grandes grupos: prefixos legítimos (PLs) e prefixos composicionais (PCs). Do ponto de vista prosódico, afirmamos que PLs são sílabas e que PCs são palavras fonológicas independentes. Os critérios para estabelecer essa distinção foram o acento e a existência como formas livres. PLs não possuem acento próprio e são formas presas, ao contrário dos composicionais. Além disso,
PLs são todos monossilábicos, enquanto PCs são tanto mono quanto dissilábicos.

Tentamos estender esses mesmos critérios ao espanhol, mas constatamos que apenas o primeiro é válido para esta língua. Está exemplificado em (1) e (2).

(1) PLs

$\mathrm{PB} \quad$ a. $\left[\mathrm{re}_{\mathrm{sil}}\left[\text { analisár }_{\mathrm{PW}}\right]_{\mathrm{PW}}\right.$

EP b. $\left[\mathrm{re}_{\text {sil }}[\text { hacér }]_{\mathrm{PW}}\right]_{\mathrm{PW}}$

PB e EP c. *Agora vou re os trabalhos. (reanalisar)

d. *Debes re tu trabajo. (rehacer)

(2) PCs

PB e EP a. [[súper $\left.]_{\mathrm{PW}}[\text { mercádo }]_{\mathrm{PW}}\right]_{\mathrm{PW}}$

PB b. o ex de Maria. (ex-namorado)

EP c. *el ex de María. (ex-novio)

Quanto ao acolchetamento, observamos um comportamento análogo nas duas línguas: em (1a,b), temos uma sílaba que se liga a uma base, que é uma palavra fonológica; em (2a), ao contrário, dado que estamos diante de duas formas acentuadas, temos uma palavra fonológica-base à qual se afixa outra palavra. ${ }^{1}$ Sobre essa representação, é importante dizer, ainda, que temos de admitir, aqui, a recursividade da palavra fonológica - abordagem já bastante aceita na literatura (Selkirk,1995; Peperkamp, 1997; Vigário, 2001).

Quanto à distinção entre formas livres e presas, podemos dizer que as formas de (1) se comportam como formas presas nas duas línguas, enquanto as formas de (2), apesar de poderem

Luiz Carlos Schwindt é professor do Instituto de Letras da UFRGS.

*Este trabalho contou com a colaboração dos bolsistas Aline Grodt (IC-FAPERGS) e André Schneider (BIC-UFRGS). Versões anteriores do mesmo foram apresentadas, no ano de 2003, no II ECLAE, na UFPB, e no III Congresso Internacional da ABRALIN, na UFRJ. 
aparecer como formas livres em PB, não admitem existência isolada no EP. ${ }^{2}$ Essa constatação nos fez rever a categoricidade de tal argumento: admitimos, pois, que a existência como forma livre só pode ocorrer com este tipo de prefixo (composicional), mas não é necessariamente uma condição para garantir a distinção entre os dois tipos de prefixos. Em outras palavras: cremos que só palavras fonológicas possam existir isoladamente, mas nem todas existam efetivamente. Em (3), a seguir, mostramos que mesmo o PB, que, como afirmamos, aceita a existência de PCs isolados, falha muitas vezes nesse aspecto.

a. João estava conversando com seu ex-chefe.

b. *João estava conversando com seu ex. (agramatical, com ex no sentido de chefe)

Diagramamos em (4) e (5) nossa idéia sobre a configuração prosódica dos prefixos em PB e EP.

(4)

Estrutura prosódica do PC

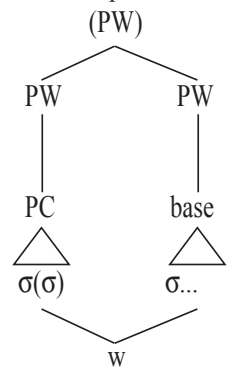

Considerando que PCs são PWs independentes, ainda que ligados por uma palavra mais alta, seu comportamento fonológico será o das palavras em geral. PLs, diferentemente, estarão sujeitos a algumas particularidades - razão por que neste artigo nos deteremos nessa segunda categoria.

\section{PLs transparentes em PB e EP: uma proposta conciliadora entre regras morfológicas e estratificação do léxico}

\subsection{Dados}

O critério para seleção dos dados que serão apresentados foi, sobretudo, o da transparência sincrônica, ou seja, procurou-se assegurar que os dados só contivessem prefixos 'percebidos' pelos falantes do PB e do EP. O fato é que esse critério por vezes é pouco seguro, talvez por pesar demais a influência da escrita no julgamento dos falantes. Nesse sentido, então, procuraram-se, sempre que possível, exemplos de formações novas nas duas línguas. Isso permitiu, inclusive, verificar que os conceitos de transparência sincrônica e produtividade não estão cem por cento relacionados em se tratando de prefixação nesses dois sistemas. Isso vale dizer que nesse processo, como na derivação em geral (Basílio, 1980), o universo das regras de análise estrutural (RAEs) é mais amplo que o universo das regras de formação de palavras (RFPs). Nessa perspectiva, a produtividade não é, portanto, um critério suficiente para uma análise como esta.

A interação entre morfologia e fonologia, contudo, faz rever inclusive o critério da transparência. Em primeiro lugar, do ponto de vista da fonologia, pode-se dizer que quanto menos ligantes (ou, em outros termos, quanto mais próximos da superfície), os prefixos tendem a ser, mais identificados sincronicamente. Assim, aqueles prefixos que chamamos de composicionais (Schwindt, 2000) são facilmente reconhecidos e produzem palavras novas tanto em PB quanto em EP. Com isso, queremos dizer que transparência pode ser medida por outros aspectos ou em diferentes graus, isto é, por um lado temos aquela forma que todos julgam prefixada (o que tipicamente se chama de transparente) e por outro lado temos aquelas formas que, embora alguns não reconheçam como prefixada, denunciam pela fonologia, uma "operação" por parte do falante. Se adotamos o conceito tradicional de produtividade para descrever uma língua, o resultado será uma gramática com pouca abstração, mas com um dicionário pesado. Essa é uma questão complexa, que envolve dizer se usamos nossa memória mais para 'armazenar' ou mais para 'operar' (seja com regras, seja com restrições). Parece mais coerente para qualquer teoria de base gerativista a segunda opção. ${ }^{3}$

Em (6), a seguir, trazemos a relação dos prefixos monossilábicos e inacentuados que julgamos transparentes nas duas línguas. Sempre que possível, procuramos incluir exemplos de formações novas extraídos, respectivamente, de Sandmann (1989) e de Lang (1990). ${ }^{4}$

(6) a. a- (locativo - produtivo somente para criação de parassintéticos) PB abrasileirar abaratar acarinhar acaramelar aligeirar aligerar 


$\begin{array}{ll}\text { b. a- (aN-) (negação, privação) } & \\ \text { PB } & \text { EP } \\ \text { aético } & \text { acientifismo } \\ \text { apartidário } & \text { aproblemático } \\ \text { anistórico } & \text { analcohólico } \\ \text { anortografia } & \text { analérgico } \\ \text { c. co- (coN-) (posição - produtivo com valor comitativo) } \\ \text { PB } & \text { EP } \\ \text { coabitação } & \text { coadquirir } \\ \text { co-mandante } & \text { cohermanarse } \\ \text { co-patrocinar } & \text { compaternidad } \\ \text { d. deS- (diS-) (negação,privação,afastamento) } \\ \text { PB } & \text { EP } \\ \text { desburocratização } & \text { desapretar } \\ \text { desestatizante } & \text { desgobierno } \\ \text { desmalufar } & \text { desoír } \\ \text { disfonia } & \text { disfunción } \\ \text { e. eN- (iN-) (posição - produtivo somente para criação de } \\ \text { parassintéticos) } & \\ \text { PB } & \text { EP } \\ \text { encompridar } & \text { encajar } \\ \text { enlameado } & \text { enlatar } \\ \text { emadeirada } & \text { enmadeirada } \\ \text { empobrecer } & \text { empaquetar } \\ \text { importar } & \text { inmersión } \\ \text { f. eS- (ex-) (procedência - produtivo somente para criação de } \\ \text { parassintéticos) } & \text { EP } \\ \text { PB } & \text { EP } \\ \text { esbagaçar } & \text { reconerdecer } \\ \text { expectorar } & \text { excavar } \\ \text { exportar } & \text { expropriar } \\ \text { g. iN- (negação,privação) } & \text { extemporáneo } \\ \text { PB } & \\ \text { ilegal } & \text { EP } \\ \text { inobservável } & \text { ilegible } \\ \text { inestético } & \text { inacabado } \\ \text { imoral } & \text { inestimable } \\ \text { intragável } & \text { inmaduro } \\ \text { h. re- (repetição) } & \\ \text { PB } & \text { reapropriar-se } \\ \text { recadastramento } & \\ \text { reprivatizar } & \\ & \end{array}$

\subsection{1 a-}

Tanto em PB quanto em EP, este prefixo só restou identificável sincronicamente em parassintéticos. Nesse sentido, sua formação parece bastante produtiva.

Quanto à conformação à estrutura silábica das duas línguas, não parece apresentar particularidades, uma vez que os dois sistemas possuem sílabas sem onset.

\subsection{2 a- (aN-)}

Este prefixo parece ser transparente nas duas

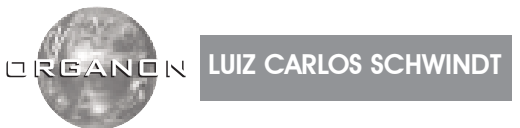

línguas. Seu comportamento é relativamente regular: diante de bases iniciadas por vogal, a nasal se superficializa; diante de bases iniciadas por consoante não. Quando, porém, a base tem a vogal inicial tônica, os falantes parecem resistir à silabificação com a coda nasal (ex. *anético). ${ }^{6}$

Uma particularidade deste prefixo é que a forma produtiva parece ser a sem nasal, o que quer dizer que uma forma como a-histórico poderia ser encontrada, mas *ampartidário não, o que sugere que $a N$ - está no curso de sua lexicalização.

\section{$3.1 .3 \mathrm{co}-(\mathrm{coN}-)$}

A questão aqui é semelhante a de $a N$-: $c 0-$ parece ser o prefixo produtivo e não $c o N$-. Um exemplo disso é o vocábulo co-mandante, expresso em (4c), que alterna com comandante, com sentidos diversos. Além disso, co- se liga a bases iniciadas tanto por vogal quanto por consoante, enquanto $\mathrm{coN}$ só se liga a bases que começam por consoante. Ainda, qualquer forma com $c o N$ - poderia, em princípio, ser dita com co- (eg. co-fraternizar), enquanto o contrário não parece possível (ex. *conhermarnarse).

No que respeita a esses dois últimos prefixos, cabe uma discussão sobre o lugar da alomorfia: se no input ou definida por regras/restrições. ${ }^{\text {? }}$

\subsection{4 des- (dis-)}

Optamos por tratar esses prefixos conjuntamente devido a seu comportamento silábico idêntico. Há que se considerar que, portadores na origem de sentidos distintos, parecem estar fundidos em PB moderno, dada a tendência de /e/ converterse em [i] na pauta pretônica. Apesar de tal fenômeno não estar presente no EP, estes prefixos muitas vezes também se fundem semanticamente, como se observa em exemplos como disgusto / desfavor. É evidente, contudo, que falantes de PB e EP não dirão

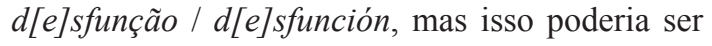
explicado pela via da lexicalização. Importa dizer, por fim, que tanto em PB quanto em EP, apenas deS- é um prefixo produtivo. ${ }^{8}$

Uma característica importante de deS-, na comparação entre os dois idiomas, é o fato de o $S$ vozear-se em $\mathrm{PB}$ em contextos em que precede um segmento vozeado e o mesmo não ocorrer em EP. Essa é uma característica não do prefixo, mas da sílaba portuguesa e espanhola propriamente ditas.

Outro fato importante é a epêntese que se cria quando prefixos encontram bases do tipo $S C$, 
como desesperado, destruído. Uma possibilidade de análise, neste caso, seria postular que as formas sem epêntese seriam todas lexicalizadas e que todos os processos produtivos teriam de se submeter a ela. Essa é a posição de Colina (1995:198) e também de Peperkamp (1997:92), que consideram esse tipo de prefixação não-transparente.

Esse argumento, todavia, teria de ser estendido ao prefixo $i N$-, que faz claramente a seguinte distinção: significando movimento para dentro, não admite epêntese; significando negação, sempre a exige. Teríamos, assim, de admitir que todo prefixo $i N$ - significando movimento para dentro não é transparente. Essa, em nosso entendimento, não parece ser uma alternativa interessante, no mínimo pelas três razões que apresentamos a seguir. Primeiro, porque o paradigma de vocábulos prefixados como inscrever, descrever / inspirar, expirar, transpirar etc. parece sugerir uma relação de oposição semântica de plena consciência dos falantes. Segundo, porque esse mesmo processo de epêntese mostra-se bastante produtivo com estrangeirismos em PB e também em EP, como [i]scaner, [i]skol etc., o que sugere que o vocábulo passa pelas regras de formação conhecidas pelos falantes. Terceiro, é preciso dizer que tanto em $\mathrm{PB}$ quanto em EP o prefixo $e N$-(iN-) é muito produtivo nas formação de parassintéticos, como se observa nos exemplos de $(6 e)$.

Em Schwindt (2000) propusemos que prefixos com essa epêntese pertenciam ao nível da palavra, considerando que se anexavam a bases que têm existência isolada.

\section{$3.1 .5 \mathrm{eN}-\left(\mathrm{iN}\right.$ - $\left._{\text {dentro }}\right)$}

Inicialmente, é preciso dizer que não estabelecemos distinção entre $e N-$ e $i N$ significando movimento para dentro, por terem comportamentos semelhantes e pela forte tendência em PB de elevação da vogal $E$ na seqüência $e N$ em início de vocábulo. Caracterizam-se, pois, por terem uma só forma subjacente.

Este prefixo, como afirmamos, é produtivo na formação de parassintéticos e, como tal, se liga a bases em formação como em empaquetar, que não admite as formas *empaquete ou *paquetar. Dizemos, então, que prefixo e sufixo, neste caso, pertencem ao mesmo nível derivacional. Como sufixos carregam acento em PB e EP, obrigamo- nos a admitir que este prefixo pertence ao primeiro nível do léxico.

\subsection{6 es- (ex-)}

Este prefixo também é bastante produtivo na formação de parassintéticos nos dois idiomas. Nesse sentido, contudo, pode gerar alguma confusão com a epêntese anteriormente mencionada, isto é, num vocábulo como $e S+$ stat $+i z a r$, alguém poderia aventar que, ao contrário da epêntese, temos uma forma prefixada. Se assim fosse, a forma básica teria de ser tat- ou stat-. A primeira seria prontamente rejeitada, em função da presença desse $\mathrm{S}$ em todas as formas derivadas deste vocábulo; a segunda, exigiria que os dois Ss se convertessem num só, por força do OCP - o que parece bastante plausível.

Rejeitamos, todavia, esta idéia, porque temos evidências de que este $e S$ - está associado à presença de um sufixo em vocábulos como esbarrar (que não tem o $\mathrm{S}$ na base) e, ao mesmo tempo, aparece em bases como estado, em que não há nenhum sufixo. Optamos, então, por admitir que este $e S$ está no input, no caso do prefixo.

\subsection{7 $\mathrm{iN}_{\text {neg }}{ }^{-}$}

Trata-se de um prefixo bastante produtivo, tanto em PB quanto em EP, que se liga, sobretudo, a bases de adjetivos e substantivos (lugar, nos verbos, de deS- e não-). Como dissemos, só se liga a palavras prontas, tendo-se como evidência a obrigatoriedade da epêntese quando se relaciona com bases iniciadas por $S C$. O PB tem uma única exceção, o vocábulo instável que, para reforçar sua excepcionalidade, tem, em EP, como forma sincrônica inestable.

\section{1 .8 re-}

Trata-se de um prefixo bastante controverso no PB. Ocorre que, apesar de acomodar-se às exigências do primeiro nível do léxico, re-se junta a bases iniciadas por E e aceita que essa vogal se eleve, produzindo formas como re[i]xaminar. Considerando que este é um processo que até agora se tem tratado como variável, seu lugar, em princípio, seria o pós-léxico. Estaríamos, portanto, diante de um paradoxo de ordenamento. O fato é que acreditamos cada vez mais que as regras que convertem $e$ em $i$ podem ter, em nosso idioma, características de regras lexicais, sobretudo com 
aplicações que beiram o categórico, como é o caso dessa elevação. ${ }^{9}$ Esse argumento, aliás, é coerente com nossa decisão de fundir $d e S$-/diS- e eN-/iN-. ${ }^{10}$

\subsection{Estratificação do léxico e os conceitos de produtividade/transparência}

Antes de apresentar nossa estratificação do léxico, queremos recuperar as duas classes de PLs que propusemos para o $\mathrm{PB}$, numa abordagem de regras da LPM (Schwindt,2000), e que agora estendemos ao EP.

a) PLs de classe I: relacionam-se com bases em formação (por ex. participam da parassíntese; situam-se na posição mais interna no caso de sobreposição de prefixos, em relação a prefixos de classe II);

b) PLs de classe II: relacionam-se com a palavra pronta (por ex., ocorrem depois da epêntese inicial; não participam da parassíntese; admitem estar à esquerda de prefixos de classe I, no caso da sobreposição de prefixos).

Essa divisão, todavia, não repercutia em diferenciação prosódica desses prefixos.

Peperkamp (1997), numa análise de restrições, propõe que prefixos não-produtivos/ não-transparentes formam uma única palavra fonológica com a base. O mesmo faz Vigário (2001), em sua análise da palavra prosódica em português europeu.

Tal visão tem, em nosso entendimento, dois problemas: (i) confunde-se produtividade com transparência - conceitos, como já vimos, que dizem respeito a operações lexicais distintas; e (ii) perde-se a informação morfológica, isto é: prefixo não-transparente não é prefixo - é radical. ${ }^{11}$

Por isso, propomos que as noções de produtividade e transparência sejam reinterpretadas à luz de uma análise estratal, na linha de Kiparsky $(1985 ; 1998) .^{12}$

No léxico profundo (ou no dicionário) estariam formas não-transparentes e nãoprodutivas; no nível 1 , formas transparentes mas não necessariamente produtivas; no nível da palavra, apenas formas produtivas. Isso estabeleceria uma ponte entre Fonologia e Morfologia Lexical e a abrangência de Regras de Análise Estrutural e Regras de Formação de Palavras - as primeiras com uma abrangência maior, ativas ao longo de todo o léxico; as segundas obrigatoriamente ativas somente no nível $2 .{ }^{13}$
OS PREFIXOS E O LÉXICO DO PB E DO EP

\begin{tabular}{|c|c|c|}
\hline \multicolumn{3}{|c|}{ LÉXICO PROFUNDO (itens não-transparentes) } \\
\hline 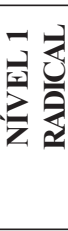 & $\begin{array}{l}\text { MORFOLOGIA } \\
\text { PL's I (incorporados) } \\
\text {... } \\
\text { RAEs obrig. } \\
\text { RFPs opc. }\end{array}$ & $\begin{array}{l}\text { FONOLOGIA } \\
\text { Epêntese } \\
\ldots\end{array}$ \\
\hline$\frac{N}{Z}$ & $\begin{array}{l}\text { MORFOLOGIA } \\
\text { Prefixos: } \\
\text { PL's II (adjuntos) } \\
\text { PC's } \\
\ldots \\
\text { RAEs obrig. } \\
\text { RFPs obrig. }\end{array}$ & $\begin{array}{l}\text { FONOLOGIA } \\
\text { Neutr. pretônica } \\
\ldots\end{array}$ \\
\hline \multicolumn{3}{|c|}{$\begin{array}{l}\text { PÓS-LÉXICO } \\
\text { Compostos } \\
\text { sintáticos } \\
\text { Regras variáveis... }\end{array}$} \\
\hline
\end{tabular}

Considerando que nosso objetivo aqui é descrever prosodicamente os prefixos (apesar de termos feito considerações sobre características lexicais de cada um dos prefixos), não nos preocupamos neste trabalho em definir que prefixos se acomodam em cada classe, já que isso exige um cuidadoso exame dos processos fonológicos envolvidos em cada língua e também de aspectos morfológicos, como a parassíntese e a dupla prefixação. ${ }^{14}$

\section{CONSIDERAÇÕES FINAIS}

Neste texto, a partir da análise de Schwindt (2000), apresentamos uma proposta de configuração prosódica de prefixos monossilábicos inacentuados em português brasileiro e espanhol peninsular, na perspectiva da Fonologia Prosódica (Selkirk, 1984, 1986; Nespor \&Vogel, 1986).

Discutindo os trabalhos de Peperkamp (1997) - acerca do italiano e do espanhol - e de Vigário (2001) - sobre o português europeu -, procuramos reunir dados das duas línguas em foco para sustentar a premissa de que essas línguas possuem dois tipos de PLs: aqueles que se incorporam à palavra fonológica e aqueles que se adjungem a esta.

Por fim, apresentando uma proposta de estratificação do léxico, na linha de Kiparsky $(1985 ; 1998)$, sugerimos que prefixos que sofrem incorporação são transparentes apesar de muitas vezes não serem produtivos, e se acomodam no nível 
da raiz; prefixos, por outro lado, que sofrem adjunção, são transparentes e produtivos e se acomodam no nível da palavra. Prefixos totalmente lexicalizados, isto é, que não são mais transparentes, estão listados no léxico profundo.

\section{REFERÊNCIAS BIBLIOGRÁFICAS}

BASÍLIO, M. (1980). Estruturas lexicais do português: uma abordagem gerativa. Petrópolis: Vozes.

BOOIJ, G. \& RUBACH, J. (1984). Morphological and prosodic domains in lexical phonology. Linguistic Inquiryi 18: 1-44.

BOOIJ, G. \& LIEBER, (1993). On the simultaneity of morphological and prosodic structure. In: S. Hargus and E. Kaisse (eds) Studies in Lexical Phonology. San Diego: Academic Press, 23-44.

COHN, A. (1989). Stress in Indonesian and Bracketing Paradoxes. Natural Language and Linguistic Theory 7, 167-216.

COLINA, S. (1995). A constraint-based analysis of syllabification in Spanish, Catalan, and Galician. PHD dissertation. University of Illinois at UrbanaChampaign.

HARRIS, J.W. (1983) Syllable structure and stress in Spanish. A nonlinear analisys. Cambridge, Mass.: MIT.

KIPARSKY, P. (1985) Some consequences of lexical phonology. Phonology yearbook, 2:85-138. London: Cambridge University Press.

. (1998). Opacity and Paradigm effects. Stanford: CSLI. ms.

LANG, M.F. (1990). Formación de palabras en español. Morfología derivativa productiva en el léxico moderno. Madrid: Cátedra.

NARO, A.J. (1973). Estudos diacrônicos. Petrópolis: Vozes.

NESPOR, M. \& I.VOGEL (1986) Prosodic phonology. Dordrecht-Holland: Foris Publications. PEPERKAMP, S. A. (1997). Prosodic Words. Holland: HIL dissertations.

SANDMANN, A. J. (1989) Formação de palavras - no português brasileiro contemporâneo. Curitiba: Ed. da UFPR.

SCHWINDT, L.C. (2000). O prefixo no português brasileiro: análise morfofonológica. Tese de doutorado. Porto Alegre:PUCRS, 2000.

. (2001). O prefixo no português brasileiro: análise prosódica e lexical. DELTA. v.17, n.2. São Paulo: EDUC PUC.
. (2002). O prefixo e a silabificação em PB: um exercício em LPM-OT. Letras de Hoje. v.37,n.1. Porto Alegre:PUCRS.

SELKIRK, E. (1984). Phonology and syntax. The relation between sound and structure. Cambridge, MA: MIT Press.

. (1986). On derived domains in sentence phonology. Phonology Yearbook 3, 371-405.

- (1995). The prosodic structure of function words. In J. Beckman, L. Walsh-Dickey \& S. Urbanczyk (eds). University of Massachusetts Occasional Papers in Linguistics: Papers in Optimality Theory, 439-469. Amherst:GLSA.

VARELA, S. (1999). La prefijación. In: BOSQUE , I. \& DEMONTE, V. Gramática descritiva de la lengua espanhola. Entre la oración y el discurso. v.3 Real Academia Española. Madrid: ESPASA. VIGÁRIO, M. (2001). The prosodic word in european portuguese. Tese de doutorado. Lisboa: Universidade de Lisboa.

WETZELS, W. L. (1992) Mid vowel neutralization in brazilian portuguese. Cadernos de estudos lingüísticos, 23:19-55. Campinas: UNICAMP.

Notas:

${ }^{1}$ Estamos admitindo, aqui, que é o acento o caracterizador da PW - uma visão radical da idéia de Nespor \& Vogel (1986). Rejeitamos, ainda, a necessidade da restrição de minimalidade, como faz Peperkamp (1997), visto que o PB, como o EP, possui muitos monossílabos tônicos. Não é, portanto, o número de sílabas que garante a estrutura de PWs nessas línguas.

${ }^{2}$ Importante é frisar o fato de que o espanhol, ainda que possuindo processos de redução vocabular, não usa prefixos como formas livres - isso poderia ser considerado mais uma evidência de que esse fenômeno não se confunde com outros processos de redução.

${ }^{3}$ É evidente que há "operações" que ficaram no passado, o que não serviria para estabelecer um critério de transparência.

${ }^{4} \mathrm{O}$ prefixo $s u b$-, por nós tratado como PL em 2000, ficou fora deste momento da análise por apresentar um comportamento bastante ambíguo no PB: apesar de entrar na formação do parassintético subterrâneo, admite existência isolada. Em espanhol, diferentemente, parece bem mais preso à base.

${ }^{5}$ Em espanhol, re-pode também ter um sentido semelhante ao dos sufixos -azo ou -ote, isto é, o de reforçar a idéia da base, por ex. rebueno, reguapo. Do ponto de vista morfofonológico, cremos que vá se comportar como o re- iterativo.

${ }^{6}$ Ainda que isso exista em formas não-transparentes, como anoxítono.

${ }^{7}$ Numa perspectiva de otimidade, a pergunta seria: quem decide a alomorfia neste caso: o input ou o ranking? Embora não seja esse o nosso foco de interesse aqui, convém registrar que entendemos que a alomorfia deva ser deduzida do ranking sem estipulação no input. Isso nos obriga a admitir uma restrição 
fonotática que impedirá as seqüências aN- + Base $\left[\mathrm{C}, \mathrm{V}_{\text {tônica }}\right.$. Além do acúmulo de informações aí presentes, ainda temos uma situação em que o output terá de olhar para a base para decidir sua forma. Outra alternativa, talvez menos custosa, é se admitirem níveis de análise, como propõe Kiparsky (1998), na LPM-OT.

${ }^{8}$ deS- carrega, todavia, nas duas línguas, inúmeras nuances de significado, as quais não nos interessam neste momento. Além disso, esse prefixo apresenta ainda a variante $\operatorname{sem} S$, da qual não trataremos agora.

${ }^{9}$ Ainda carece de exame quantitativo, mas o que vemos é que esta elevação, que atinge também $e S$-, é quase categórica e forma, curiosamente,em grande quantidade, hiatos em vez de ditongos, quando se encontra a seqüência $E E$ - o que estaria de acordo com o que se espera no léxico.

${ }^{10}$ Sobre tal 'fusão', ver Naro (1973).

${ }^{11}$ Nesse sentido, é importante dizer que Peperkamp assume a hipótese de Booij \& Rubach (1984); Cohn (1989) e Booij \& Lieber (1993) de que a estrutura prosódica e a estrutura morfológica estão presentes simultaneamente mas não interagem.

${ }^{12}$ No momento não estamos nos posicionando sobre uma perspectiva de regras ou de restrições, razão por que citamos as duas obras de Kiparsky.

${ }^{13}$ Wetzels (1992) já propunha que a formação produtiva do PB estaria no nível 2 do léxico.

${ }^{14}$ Para o PB, esse exercício pode ser visto em Schwindt (2000). 